\title{
Klavikula kaynamamaları
}

\author{
Clavicular non-unions
}

\author{
Mehmet Kapıcıoğlu, Kerem Bilsel
}

Bezmialem Vakıf Üniversitesi Ortopedi ve Travmatoloji Anabilim Dalı, İstanbul

\begin{abstract}
Klavikula kırıkları; erişkin kırıkların \%2,6-4'ünü, omuz çevresi kırıklarının \%35'ini oluşturur. Geleneksel olarak klavikula kırıkları konservatif olarak tedavi edilir. Eski makalelerde geleneksel konservatif tedavi edilmiş klavikula kırıklarında kaynamama \%1'ler civarında bildirilmiş olmakla beraber, yeni yapılan bir meta-analizde kaynamama oranının daha yüksek olduğu bildirilmiştir. Bu nedenle, kaynamama ile sonuçlanacak kırıkların önceden tahmin edilebileceği ve istenmeyen sonuçlar oluşmadan cerrahi tedaviyle önlenebileceği düşünülebilir. Birçok çalışmada; yaşlılık, kadın cinsiyet, 2 cm'den fazla kısalma, distal klavikula yerleşimi ve parçalanması olan kırıklarda kaynamamayla olan ilişki gösterilmiştir. Radyografik kaynamama ile semptomatik kaynamama her zaman ilişkili olmayabilir. Bu yüzden, her kırık tedavisi özel olarak değerlendirilmelidir.
\end{abstract}

Anahtar sözcükler: klavikula; kaynamama; osteosentez; distal
Clavicle fractures; $2.6-4 \%$ of adult fractures, and $35 \%$ of fractures around the shoulder. Traditionally, fractures of the clavicle are treated conservatively. Although in previous articles non-unions has been reported with the incidence of $1 \%$ for conventional conservatively treated clavicle fractures, the rate of non-union in a new meta-analysis is higher. For this reason, it can be considered that fractures that may result in non-union can be predicted and avoided by surgical treatment prior to undesirable outcomes. In many studies; age, female gender, shortening of more than 2 $\mathrm{cm}$, placement of the distal clavicle, and comminuted fractures have been shown to have a relation with non-union. Radiographic non-union and symptomatic non-union may not always be related to each other. Therefore, every fracture treatment should be evaluated separately.

Key words: clavicle; non-union; osteosynthesis; distal
K lavikula kırıkları; erişkin kırıkların \%2,6-4'ünü, omuz çevresi kırıklarının ise \%35'ini oluşturur. Anatomik olarak mediyal, orta ve lateral olmak üzere üç bölgeye ayrılır. Kırık yerleşimi, yaklaşık \%80 orta kısımda, \%15 lateralde, \%5 mediyal kısımdadır. ${ }^{[1]}$

Klavikula, ilk kemikleşen ve kemikleşme merkezi en son kapanan kemiktir. "S" şeklinde olup mediyal anteriora konveks, lateral anteriora konkavdır. Üst ekstremite ile gövdeyi bağlayan köprü vazifesi görür. Mediyal kısmı geniştir ve alt kısımdaki hayati nörovasküler yapıları (subklavian arter, ven ve brakiyal pleksus) korur. Orta kısım köprü vazifesi görür. Lateral kısım ise bağlarla omuzu taşıyarak omuz çevresi stabiliteye katkıda bulunur.

Geleneksel olarak, klavikula kırıkları sekiz bandaj ya da kol askısı ile konservatif olarak tedavi edilir. Bununla birlikte, ameliyatsız tedavinin sonuçları her zaman mükemmel değildir. Kaynamama, omuzda fonksiyon kısıtlılığı ve devam eden ağrı gibi problemlerden sakınma nedeniyle, cerrahi tedavinin popülaritesi artmıştır. ${ }^{[2]}$

Omuz kavşağı, birbiriyle ilişkili dört eklemden (skapulotorasik, sternoklavikuler, akromiyoklavikuler [AK] ve glenohumeral) oluşmaktadır. Klavikula, iki eklemle doğrudan bağlantılıdır ve kaynamamaları omuz kavşağında biyomekanik olarak bozulmalara neden olabilir.

Eski makalelerde geleneksel konservatif tedavi edilmiş ve klavikula kırıklarında kaynamama \%1'ler civarında bildirilmiş ${ }^{[3]}$ olmakla beraber, yeni yapılan bir meta-analizde, kaynamama oranının yaklaşık \%5,9, bazı özel gruplarda ise \%15'e kadar çıktığı bildirilmiştir. ${ }^{[2,4,5]}$ Konservatif tedavi evrensel olarak belli derecede yanlış kaynama ile sonuçlanır, ancak nadiren semptomatik yanlış kaynama görülür. Klavikula kaynamaması ve yanlış kaynaması, kalıcı ağrıya, omuz

- İletişim adresi: Doç. Dr. Kerem Bilsel, Bezmialem Vakıf Üniversitesi, Ortopedi ve Travmatoloji Anabilim Dalı, 34093, Fatih, İstanbul Tel: 0532 - 2918291 e-posta: kbilsel@gmail.com

- Geliş tarihi: 1 Kasım $2017 \quad$ Kabul tarihi: 1 Kasım 2017 


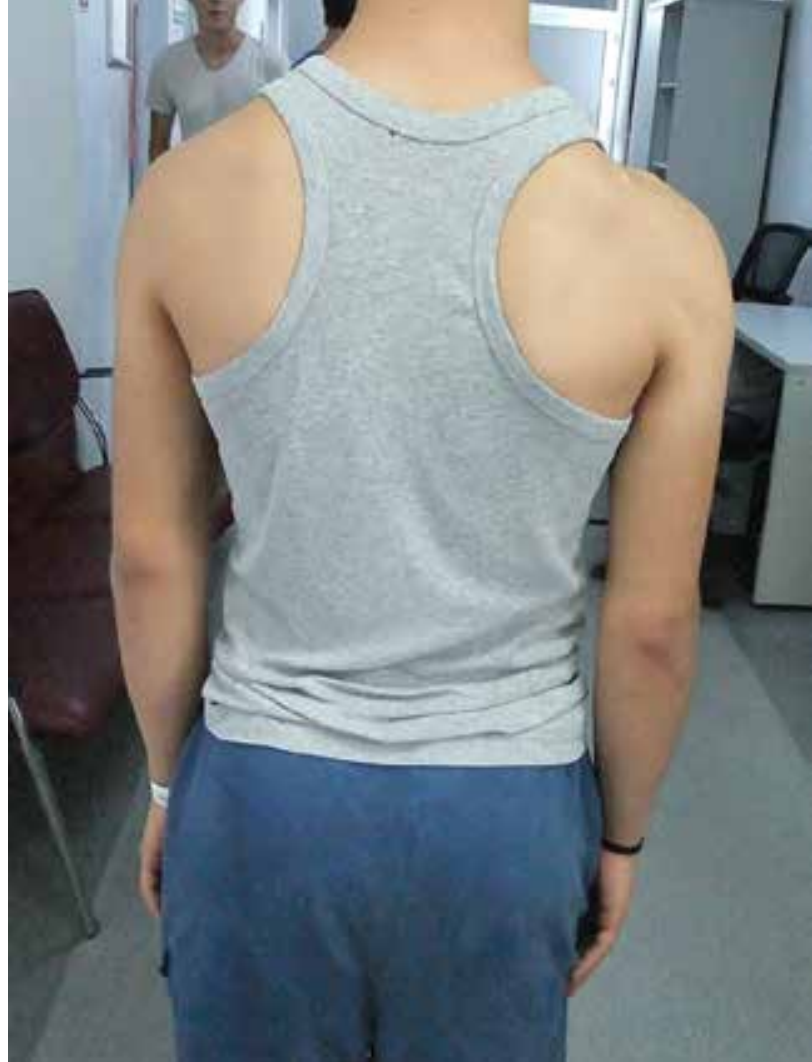

Şekil 1. Sağ klavikula kaynamaması olan bir hastanın klinik görüntüsünde görünen omuz düşüklüğü, kısalma ve postür değişikliği.

fonksiyon kısıtlılığına ve kozmetik problemlere neden olabilir (Şekil 1). Bu komplikasyonlardan sakınmak için cerrahi tedavi ön plana çıkmakla beraber, cerrahi tedavinin komplikasyonları da görülebilir. Primer osteosentezde \%3,7-4,6 arasında kaynamama bildirilmiştir. Osteosentez sonrası kaynamama sıklıkla asemptomatiktir; bazı hastalarda omuzda kuvvetsizlik, ağrı, kozmetik problem ve nevralji görülebilir. ${ }^{[6,7]}$

Klavikula kaynamamalarının omuz kavşağında fonksiyonel problemlere neden olduğunu gösteren yayınlar mevcuttur. ${ }^{[4,5,8]}$ Bu nedenle, kaynamama ile sonuçlanacak kırıkları önceden tahmin edilebileceği ve kötü sonuçlar oluşmadan cerrahi tedaviyle önlenebileceği düşünülebilir. Birçok çalışmada; yaşlılık, kadın cinsiyet, 2 cm'den fazla kısalma ve parçalanması olan kırıklarda kaynamamayla olan ilişki gösterilmiştir (Şekil 2). ${ }^{9,10]}$

\section{Klavikula Kaynamaması için Risk Faktörleri ${ }^{[9-11]}$}

Klavikulada kısalma >20 mm

$>$ Kadın cinsiyet

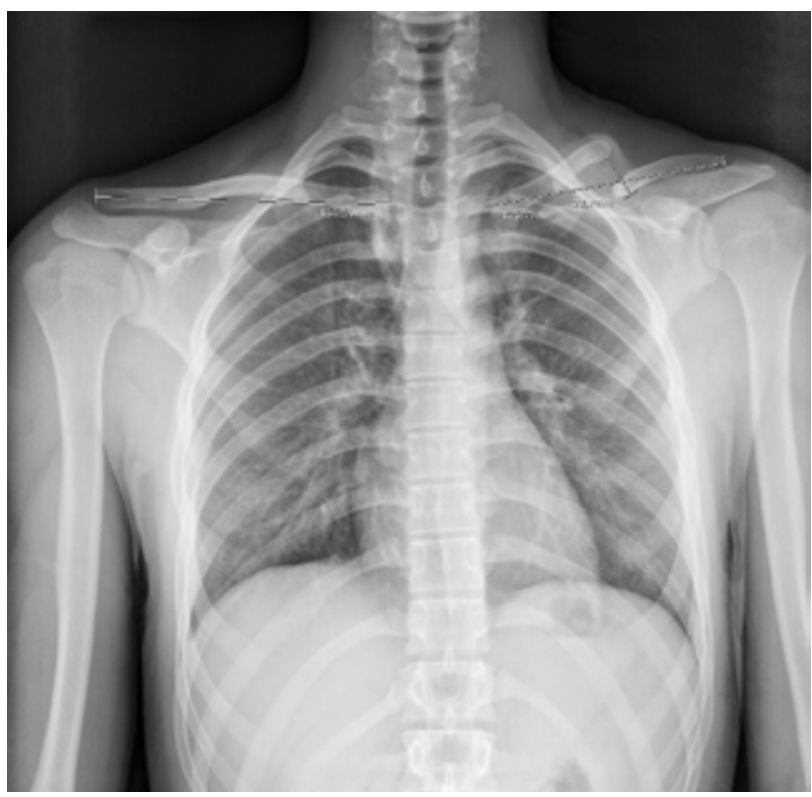

Şekil 2. Direkt karşılaştırmalı her iki klavikulayı gösteren radyografide görülen $2 \mathrm{~cm}$ 'den fazla kısalık ve deplasman.

Kırık deplasmanı ve kırık parçalanması

$>$ ileri yaş

> Yüksek enerjili travma

> Instabil lateral kırık (Neer Tip II)

Distal (lateral) klavikula krıkları, kırık instabilitesine neden olacak anatomi ve paternler nedeniyle zorluklar içerebilir. Klavikula kırıklarında en yüksek kaynamama distal klavikula kırıklarında görülür. ${ }^{[2]}$ Konservatif tedavinin kaynamama ile sonuçlanabileceği kaygısı ile, distal klavikula kırıklarına cerrahi tedavi öneren yazarlar bulunmaktadır. ${ }^{[12]}$ Distal klavikula anatomisinde AK eklem stabilitesinin iyi anlaşılması ile, tedavi planlaması daha da netlik kazanır. AK eklem horizontal stabilitesinde AK bağ ve eklem kapsülü esas rol oynar. AK eklem vertikal stabilitesinde esas rolü korakoklavikuler (KK) bağlar (trapezoid ve konoid) oynar. Trapezoid bağ, eklemden yaklaşık $2 \mathrm{~cm}$, konoid bağ ise yaklaşık 4 cm mediyaldedir. ${ }^{[13]}$

Distal klavikula kırıkları, kırık yerleşimine göre sınıflanır. KK bağ lateralinde kalan ve ekleme uzanmayan kırıklar Tip I, KK bağ lateralinde kalan ve ekleme uzanan kırıklar Tip III olarak sınıflanır. KK bağ mediyalinde kalan ve daha instabil olan kırıklar ise Tip II olarak sınıflandırılır. Konoid bağ mediyalinde kalan kırıklar Tip IIA, konoid ve trapezoid bağlar arasında kalan kırıklar Tip IIB olarak sınıflandırılır. ${ }^{[14]}$

Distal klavikula kırıkları konservatif veya cerrahi olarak tedavi edilebilir. Deplase olmamış distal klavikula 


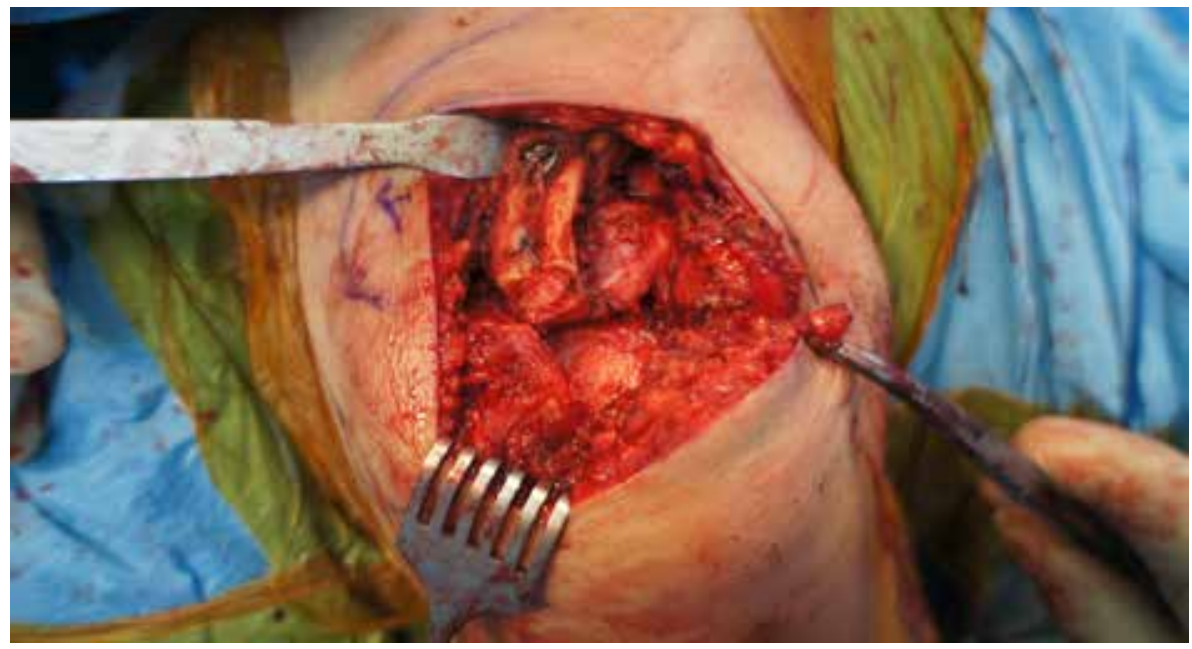

Şekil 3. Distal klavikula kaynamama olan bir olguda uygulanmış olan Weaver-Dunn prosedürü (distal klavikula rezeksiyonu, korakoakromiyal bağ augmentasyonu ve korakoklavikuler tespit).

kırıkları konservatif takip edilebilir. Örneğin, ayrışmamışTip I-III kırıklarkonservatif takip edilir. Kaynamama oranları yüksek olduğu için, Tip II kırıklarda cerrahi tedavi öne çıkmaktadır. Bazı distal klavikula kaynamamalarının asemptomatik olabileceğini belirten yazarlar vardır. ${ }^{[15]}$ Radyografik kaynamama ile semptomatik kaynamama her zaman ilişkili olmayabilir. Bu yüzden, her kırık tedavisi özel olarak değerlendirilmelidir.

\section{KLAVIKULA KIRIKLARININ TEDAVISi}

\section{Konservatif Tedavi}

Geleneksel tedavidir. Sekiz bandaj ve basit kol askısı kullanılabilir. Kırık redüksiyonu ve sonrasında, redüksiyonun sürdürülmesinde zorluklar yaşanabilir. Eski yayınlarda \%1'ler civarında kaynamama bildirilse de, güncel literatürde yaklaşık \%5,9 civarında bildirilmiştir; hatta bazı özellikli kırık tiplerinde \%15'e kadar çıkmaktadır. ${ }^{[2,4,5]}$

\section{Cerrahi Tedavi}

Açık kırıklar, yüzen omuz, cildi rahatsız eden kırık fragmanları varlı̆̆ı ve nörovasküler hasar varlığı klavikula kırıklarında cerrahi tedavi endikasyonları arasındadır. ${ }^{[2]}$ Yeni düşük profilli kilitli implant teknolojisi sayesinde cerrahi tedavinin popülaritesi artmaktadır. Cerrahi tedavi seçeneklerinde öne çıkanlar, düşük profilli kilitli vida teknolojisine sahip kompresyon plakları ve intramedüller çivi sistemleridir. Plak vida sistemleri, anatomiyi restore edip uzunluğu sağlamada etkindir ve bunlar, intramedüller çivilere göre daha stabil tespit oluşturur. Fakat plak ile tespit, intramedüller çivi ile tespite göre daha invaziv bir girişimdir. Plak vida ile tespitte; enfeksiyon, damar-sinir hasarı, kaynamama, implant yetmezliği (gevşemesi), implant çıkarılması sonrası yeniden kırık ve kozmetik problemler, rapor edilen komplikasyonlardır. ${ }^{[6,7]}$ Kozmetik problemler ile vasküler hasardan korunmak için, plak yerleşimi anterio-inferiora yerleştirilebilir. ${ }^{[16]}$

İntamedüller çivi sistemleri K-telinden intramedüller titanyum elastik çivilere kadar değişik şekilde uygulanabilir. Teknik antegrad veya retrograd uygulanabilir. Intramedüller çivi materyalinin medüller kanaldan geçecek kadar ince, anatomik şekle uyacak esneklikte ve stabiliteyi sağlayacak sağlamlıkta olması gerekir. Rotasyonel stabiliteleri zayıftır, parçalı kırıklarda kısalmayı önleme gücü zayıftır. Daha az yumuşak doku hasarı ve daha az invaziv girişim olduğu için, nörovasküler hasar riski teorik olarak daha azdır. Kaynamama riski daha fazladır. ${ }^{[17]}$

\section{KLAVIKULA KAYNAMAMALARINDA TEDAVI}

\section{Rezeksiyon}

İmplant teknolojisi gelişmeden önce yapılan, klavikulanın kısmen ya da tamamen rezeksiyonu, tarihi önemi olan bir kurtarma prosedürüdür. Omuz kavşağını ve fonksiyonlarını korumak için sakınılması gerekir. Genel olarak fonsiyonel sonuçlar kötü olmakla beraber, özellikle distal klavikula kırıklarında AK eklem artrozu varsa veya posttravmatik AK eklem artrozunda, distal klavikula rezeksiyonu ile iyi sonuçlar alınabilir (Şekil 3). ${ }^{18]}$ 


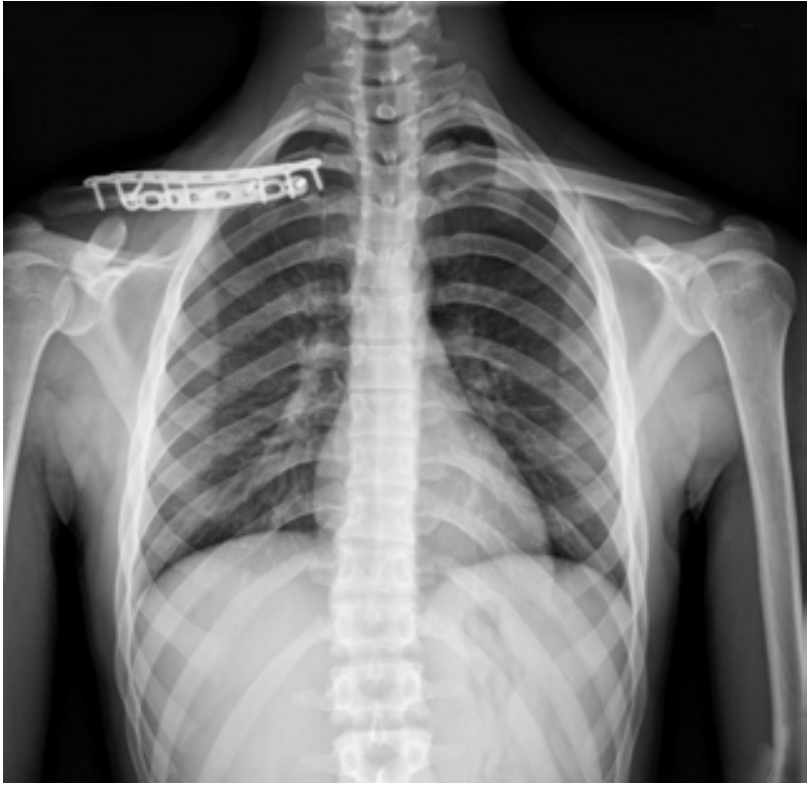

Şekil 4. Klavikula kaynamamasında uygulanmış olan superior ve anterior kombine plak vida osteosentez uygulaması direkt radyografik görünümü.

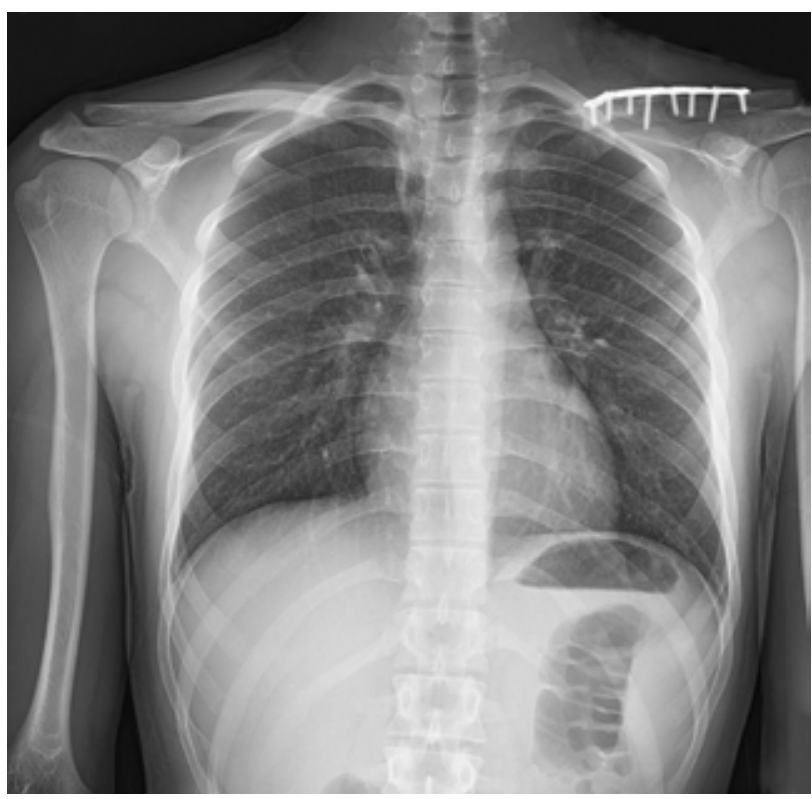

Şekil 5. Klavikula defektif kaynamaması olan bir olguda uygulanmış olan trikortikal iliak kanat otolog grefonajı ve plak bida osteosentez birinci yıl takip direkt radyografisi (orta diyafizdeki uzun vida kaynamış olarak görülen blok trikortikal iliak kanat otogreftini göstermekte).

\section{Greftleme}

Otojen iliak kanat kemik grefti, osteojenik, osteoindüktif ve osteokondüktif etkilerinden dolayı halen altın standarttır. Sınırlı kemik hacmi, kan kaybı, ameliyat süresinde uzama ve donör saha morbiditesi, kullanılırlığını sınırlar. ${ }^{[23]}$

Allogreft kemik veya demineralize kemik matriksi gibi greft alternatifleri dezavantajları en aza indirir, ancak bunlar genellikle osteokondüktiftir. Enfeksiyon risklerinde artış, rezorpsiyon hızında artış, değişken immün yanıt ve uzamış kaynama zamanı dezavantajlarıdır. ${ }^{[24]}$ Dolayısıyla, kullanılacak greftin kullanımı ve tipi hastaya ve kırık özelliklerine göre bireyselleştirilmelidir. Otolog kemik grefti ile açık redüksiyon ve plaklama kombinasyonu, atrofik kaynamama ve/veya kısalma olan durumlarda kabul edilmiş bir tekniktir ve başarılı sonuçlar bildirilmiştir (Şekil 5). ${ }^{[25,26] ~ K e m i k ~}$ greftinin her olguda gerekli olmadığını bildiren yazarlar bulunmaktadır. ${ }^{[27]}$

\section{Serbest Vaskülarize Kemik Grefti}

Cerrahi tedaviden sonra kaynaması tekrar eden olgularda kısalık da mevcutsa, vaskülarize kemik greftlerini öneren yazarlar vardır. Vaskülarize kemik grefti olarak; kosta grefti, mediyal femoral kondil grefti veya fibula grefti kullanılabilir. Bunların başarısız kaynamama larında, hem anteriora hem de superiora yer
çift plak uygulaması yapılabilir (Şekil 4). ${ }^{[22]}$ 


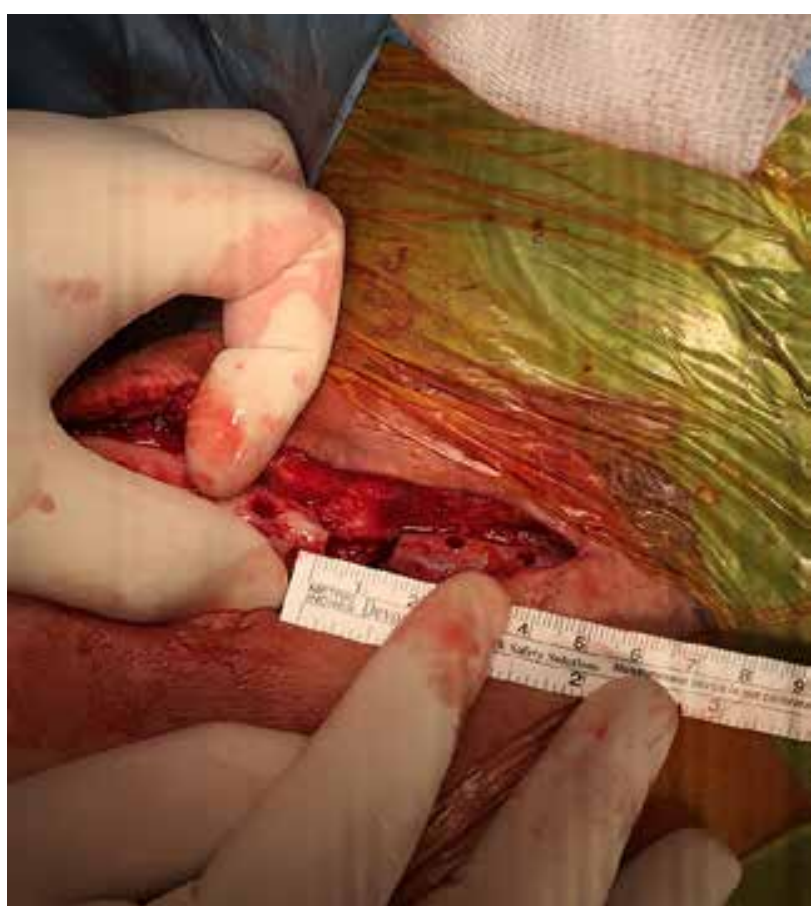

Şekil 6. Klavikula kaynamaması tedavisi sonrası tekrar kaynamama ve defekt psödoartroz görünümü.

cerrahisinden sonra deneyimli bir ekip tarafindan uygulanması önerilir. ${ }^{[28-30]}$

\section{Adjuvan Tedavi Seçenekleri}

Kemik kaynaması, biyomekanik ve biyolojik bir süreçtir. İmplant teknolojisi ile uygun biyomekanik çevre oluşturabilme becerimiz geliştirildi ancak biyolojik çevreyi etkileyen gelişmeler hızla devam etmektedir. Rekombinan kemik morfojenik proteini (BMP) hem hayvan hem klinik çalışmalarla geliş̧tirilmiş ve başarıyla kullanılmıştır. ${ }^{[31,32]}$ Klavikula kaynamamaları ile ilgili mevcut literatür bilgisi yetersiz olmakla beraber, atrofik kaynamamalarda biyolojik destek amaçlı makul bir seçenek olabilir.

\section{KOMPLIKASYONLAR}

Klavikula kaynamama cerrahi tedavisi, bir takım komplikasyonlar içermektedir. Bunlar arasında en sık görülenler; \%36 hastada \%3-8 arası kaynamama devamı, \%15 yumuşak doku komplikasyonları (keloid, hiperestezi vb.) ve \%6 implant komplikasyonları bulunmaktadır (Şekil 6). ${ }^{[3]}$ Nadiren de olsa, kırık kallusunun veya deformitenin brakiyal pleksusu ve subklavyan damarları sıkıştırması veya vida penetrasyonu bildirilmiştir. $^{[34]}$ Bildirilen komplikasyonların çoğunda; görülen teknik komplikasyonlar için dikkatli cerrahi planlama, uygun implant seçimi ve titiz cerrahi teknik, görülme sıklığını azaltabilir.

\section{KAYNAKLAR}

1. Postacchini F, Gumina S, De Santis P, Albo F. Epidemiology of clavicle fractures. J Shoulder Elbow Surg 2002;11(5):452-6.

2. van der Meijden OA, Gaskill TR, Millett PJ. Treatment of clavicle fractures: current concepts review. J Shoulder Elbow Surg 2012;21(3):423-9. Crossref

3. Neer CS 2nd. Nonunion of the clavicle. J Am Med Assoc 1960;172:1006-11.

4. Millett PJ, Hurst JM, Horan MP, Hawkins RJ. Complications of clavicle fractures treated with intramedullary fixation. J Shoulder Elbow Surg 2011;20(1):86-91. Crossref

5. Zlowodzki M, Zelle BA, Cole PA, Jeray K, McKee MD; Evidence-Based Orthopaedic Trauma Working Group. Treatment of acute midshaft clavicle fractures: systematic review of 2144 fractures: on behalf of the Evidence-Based Orthopaedic Trauma Working Group. J Orthop Trauma 2005;19(7):504-7.

6. Petrovic I, Davila S, Premuzic I, Zdunic N, Trotic R, Prutki M. Long-term outcomes of clavicular pseudoarthrosis therapy. J Surg Res 2004;121(2):222-7. Crossref

7. Martetschläger F, Gaskill TR, Millett PJ. Management of clavicle nonunion and malunion. J Shoulder Elbow Surg 2013;22(6):862-8. Crossref

8. Patel B, Gustafson PA, Jastifer J. The effect of clavicle malunion on shoulder biomechanics; a computational study. Clin Biomech (Bristol, Avon) 2012;27(5):436-42. Crossref

9. Brinker MR, Edwards TB, O'Connor DP. Estimating the risk of nonunion following nonoperative treatment of a clavicular fracture. J Bone Joint Surg Am 2005;87(3):676-7.

10. Nowak J, Holgersson M, Larsson S. Can we predict longterm sequelae after fractures of the clavicle based on initial findings? A prospective study with nine to ten years of followup. J Shoulder Elbow Surg 2004;13(5):479-86. Crossref

11. McKee MD, Wild LM, Schemitsch EH. Midshaft malunions of the clavicle. J Bone Joint Surg Am 2003;85-A(5):790-7.

12. Rokito AS, Zuckerman JD, Shaari JM, Eisenberg DP, Cuomo F, Gallagher MA. A comparison of nonoperative and operative treatment of type II distal clavicle fractures. Bull Hosp Jt Dis 2002-2003;61(1-2):32-9.

13. Renfree KJ, Riley MK, Wheeler D, Hentz JG, Wright TW. Ligamentous anatomy of the distal clavicle. J Shoulder Elbow Surg 2003;12(4):355-9. Crossref

14. Craig EV. Fractures of the clavicle. In: Rockwood CA, Green DP, Bucholz RW, Heckman JD, editors. Rockwood and Green's Fractures in Adults, 4th ed. Philadelphia, PA. Lippincott-Raven; 1996. pp.1109-93.

15. Robinson CM, Cairns DA. Primary nonoperative treatment of displaced lateral fractures of the clavicle. J Bone Joint Surg Am 2004;86-A(4):778-82.

16. Kloen P, Werner CM, Stufkens SA, Helfet DL. Anteroinferior plating of midshaft clavicle nonunions and fractures. Oper Orthop Traumatol 2009;21(2):170-9. Crossref

17. Frigg A, Rillmann P, Perren T, Gerber M, RyfC. Intramedullary nailing of clavicular midshaft fractures with the titanium elastic nail: problems and complications. Am J Sports Med 2009;37(2):352-9. Crossref

18. Simpson NS, Jupiter JB. Clavicular Nonunion and Malunion: Evaluation and Surgical Management. J Am Acad Orthop Surg 1996;4(1):1-8. 
19. Barker KL, Lamb SE, Simpson AH. Functional recovery in patients with nonunion treated with the Ilizarov technique. J Bone Joint Surg Br 2004;86(1):81-5.

20. Wu CC, Shih $\mathrm{CH}$, Chen WJ, Tai CL. Treatment of clavicular aseptic nonunion: comparison of plating and intramedullary nailing techniques. J Trauma 1998;45(3):512-6.

21. Drosdowech DS, Manwell SE, Ferreira LM, Goel DP, Faber KJ, Johnson JA. Biomechanical analysis of fixation of middle third fractures of the clavicle. J Orthop Trauma 2011;25(1):39-43. Crossref

22. Sadiq S, Waseem M, Peravalli B, Doyle J, Dunningham T, Muddu BN. Single or double plating for nonunion of the clavicle. Acta Orthop Belg 2001;67(4):354-60.

23. Szpalski M, Gunzburg R. Recombinant human bone morphogenetic protein-2: a novel osteoinductive alternative to autogenous bone graft? Acta Orthop Belg 2005;71(2):133-48.

24. Vaccaro AR, Chiba K, Heller JG, Patel T, Thalgott JS, Truumees E, Fischgrund JS, Craig MR, Berta SC, Wang JC; North American Spine Society for Contemporary Concepts in Spine Care. Bone grafting alternatives in spinal surgery. Spine J 2002;2(3):206-15.

25. O'Connor D, Kutty S, McCabe JP. Long-term functional outcome assessment of plate fixation and autogenous bone grafting for clavicular non-union. Injury 2004;35(6):575-9. Crossref

26. Olsen BS, Vaesel MT, Sojbjerg JO. Treatment of midshaft clavicular nonunion with plate fixation and autologous bone grafting. J Shoulder Elbow Surg 1995;4(5):337-44.
27. Ramoutar DN, Rodrigues J, Quah C, Boulton C, Moran CG. Judet decortication and compression plate fixation of long bone non-union: is bone graft necessary? Injury 2011;42(12):1430-4. Crossref

28. Fuchs B, Steinmann SP, Bishop AT. Free vascularized corticoperiosteal bone graft for the treatment of persistent nonunion of the clavicle. J Shoulder Elbow Surg 2005;14(3):264-8. Crossref

29. Momberger NG, Smith J, Coleman DA. Vascularized fibular grafts for salvage reconstruction of clavicle nonunion. J Shoulder Elbow Surg 2000;9(5):389-94. Crossref

30. Werner CM, Favre P, van Lenthe HG, Dumont CE. Pedicled vascularized rib transfer for reconstruction of clavicle nonunions with bony defects: anatomical and biomechanical considerations. Plast Reconstr Surg 2007;120(1):173-80. Crossref

31. Garrison KR, Shemilt I, Donell S, Ryder JJ, Mugford M, Harvey I, Song F, Alt V. Bone morphogenetic protein (BMP) for fracture healing in adults. Cochrane Database Syst Rev 2010;(6):CD006950. Crossref

32. Giannoudis PV, Kanakaris NK, Dimitriou R, Gill I, Kolimarala $\mathrm{V}$, Montgomery RJ. The synergistic effect of autograft and BMP-7 in the treatment of atrophic nonunions. Clin Orthop Relat Res 2009;467(12):3239-48. Crossref

33. Der Tavitian J, Davison JN, Dias JJ. Clavicular fracture non-union surgical outcome and complications. Injury 2002;33(2):135-43.

34. Johnson B, Thursby P. Subclavian artery injury caused by a screw in a clavicular compression plate. Cardiovasc Surg 1996;4(3):414-5. 